\title{
NOTA SOBRE A ESTRATIGRAFIA DO GRUPO BAMBUÍ NA REGIÃO DE FELIXLÂNDIA, MINAS GERAIS
}

\author{
J. G. PARENTI COUTO*
}

\begin{abstract}
A new stratigraphic unity, named Felixlândia Member (Três Marias Formation), was identified in the central part of Minas Gerais State. This identification was possible due to the field research works developed by the Metamig in the region located north of the Felixlândia city. The Felixlândia Member is made up of stromatolitic dolomites, breccias, and intraformacional conglomerates. The Bambui Group in this region is represented by Paraopeba (Unities A, B and C), Três Marias, and Pirapora Formation.
\end{abstract}

INTRODUÇÃo As informaçðes aqui reportadas foram obtidas com os trabalhos de pesquisa geológica levados a efeitos pela Metamig na região norte da cidade de Felixlândia, situada na parte central do Estado de Minas Gerais. A estratigrafia seguida é a proposta por Couto et al.(1978), com algumas modificaçð̃es introduzidas em função de aspectos novos e esclarecedores, evidenciados com os trabalhos de pesquisa, principalmente os obtidos por sondagens. O Grupo Bambuí na área está representado pelas formaçð̌es Paraopeba, Três Marias e Pirapora.

FORMAÇÃo PARAOPEBA Esta unidade aflora em grande parte da área, constituindo-se de monótono pacote de siltito argiloso plaqueado, com finas lentes de calcário siltoso e margoso. As melhores informaçðes sobre essa formação foram obtidas pelos furos de sonda, quando então se compreendeu melhor sua constituição e suas relaçðes de contato com a unidade sobrejacente. Foram identificadas três unidades litológicas com características próprias denominadas, da base para o topo, A, B e C. Dessas três unidades, apenas a superior é aflorante na área. Caracteriza-se a unidade A por um ritmito síltico-argiloso, cinza-esverdeado (de cinza-escuro a negro, quando carbonoso), carbonatado, com margas e calcários cinza-negros (às vezes oolítico) subordinados. São abundantes as estruturas sedimentares (laminações cruzadas, estrutura tipo flaser, estratificação cruzada). A espessura máxima observada é de $93 \mathrm{~m}$. A unidade média (unidade B) é constituída por margas e argilito-siltoso (carbonoso, carbonatado), com calcário (margoso) cinza-negro subordinado. Tem espessura variando de 44 a $51 \mathrm{~m}$. A superior (unidade C) mostra-se como um monótono pacote de siltito argiloso, de verde a cinza-esverdeado (de cinza-escuro a negro, quando carbonoso), plaqueado com calcário siltoso e margoso e argilito siltoso, subordinados e espessura variando de 135 a $140 \mathrm{~m}$.

Um traço comum às três unidades é dado pela presença de material carbonoso e ocorrência de pirita finamente dispersa. A passagem da unidade A para a unidade B é brusca e, desta para a unidade $\mathrm{C}$, gradacional.
FORMAÇÃo TRÊS MARIAS Esta formação é constituída, em sua maior parte, por siltitos e arenitos arcoseanos (granulometria areia fina a muito fina), de verdes a cinza-esverdeados e, subordinadamente por argilito siltoso da mesma coloração. A maior espessura do conjunto, observada nos furos de sonda, foi de $188 \mathrm{~m}$, porém sua real espessura foi obtida em perfil na serra do Boiadeiro onde estão expostos a base e o topo. Neste perfil, apresenta uma espessura de $189 \mathrm{~m}$.

Esta unidade é marcada na base por uma camada de dolomito calcítico conglomerático, de cinza a cinzaescuro, com estruturas 'estromatolíticas que se sobrepõem ou se intercalam a conglomerados e brechas de caráter intraformacional, apresentando uma espessura quase uniforme em torno de $1,80 \mathrm{~m}$, apenas quebrada no morro da Cabeça onde uma espessura mínima de $8 \mathrm{~m}$ foi observada. Para não ser confundido com alguns tipos de conglomerados ocorrentes no Grupo Bambuí não suficientemente descritos e, principalmente, por não se enquadrar em nenhuma unidade estratigráfica descrita na literatura, foi denominado Membro Felixlândia (Couto, 1979), por situar-se sua mais expressiva ocorrência próxima a essa cidade.

O contato da Formação Três Marias com a unidade sobrejacente se faz de maneira brusca, porém concordante.

MEMBRO FELIXLÂNDIA Couto et al. (1978), ao proporem uma divisão para o Grupo Bambuí, em particular a redefinição da Formação Três Marias, situaram o conglomerado calcífero como pertencentes à Formação Três Marias, porém não em sua base e, sim, próximo a ela. Este quadro não foi totalmente modificado mas, em função dos novos dados obtidos com os trabalhos de pesquisa, foi possível ampliar os conceitos então formulados. Assim, em vez de constituir-se apenas de conglomerado, como os poucos afloramentos então visitados pareciam sugerir, ele se constitui, na realidade, de um pacote de dolomito com estromatólitos laminados (plano-convexo), onde a participação de brechas e conglomerados, de caráter intraformacional, varia de uma área para outra, havendo locais onde estes 


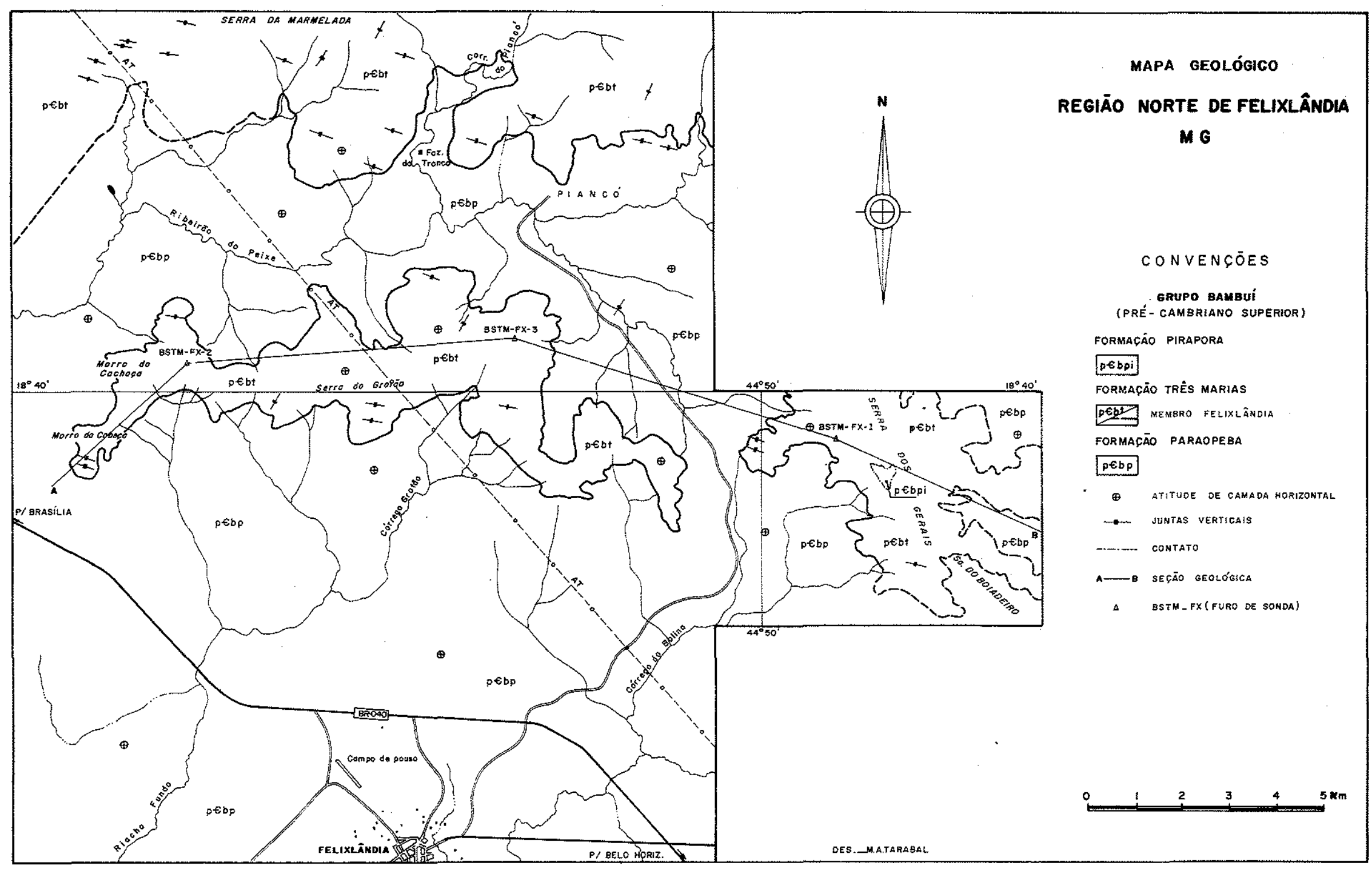


SEGĀO GEOLÓGICA

$\wedge$

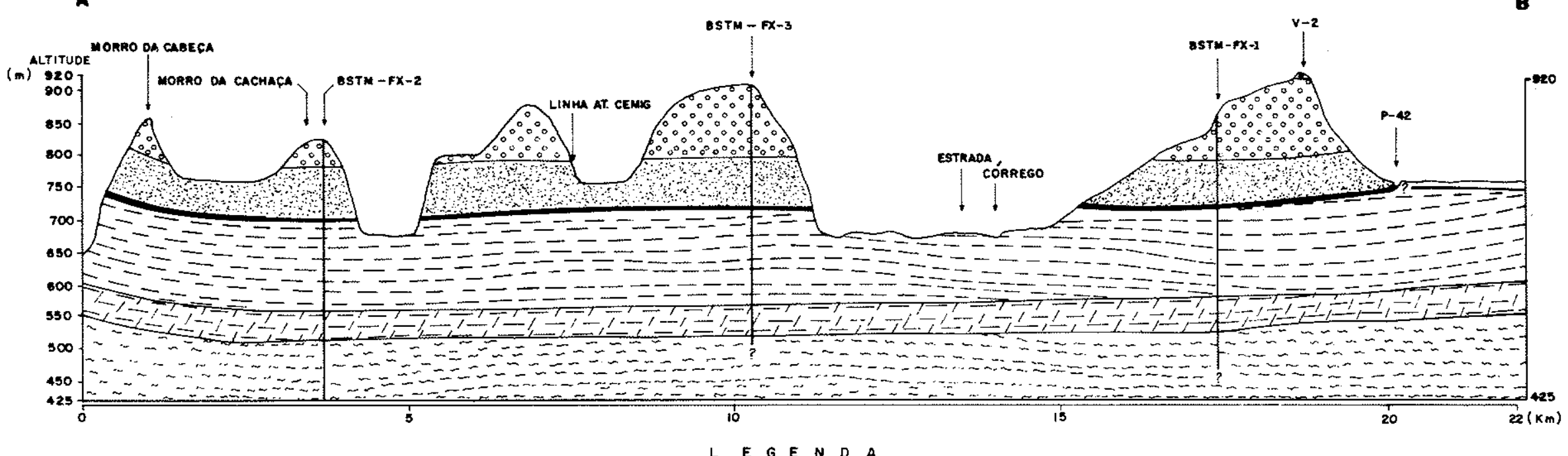

LEGENDA
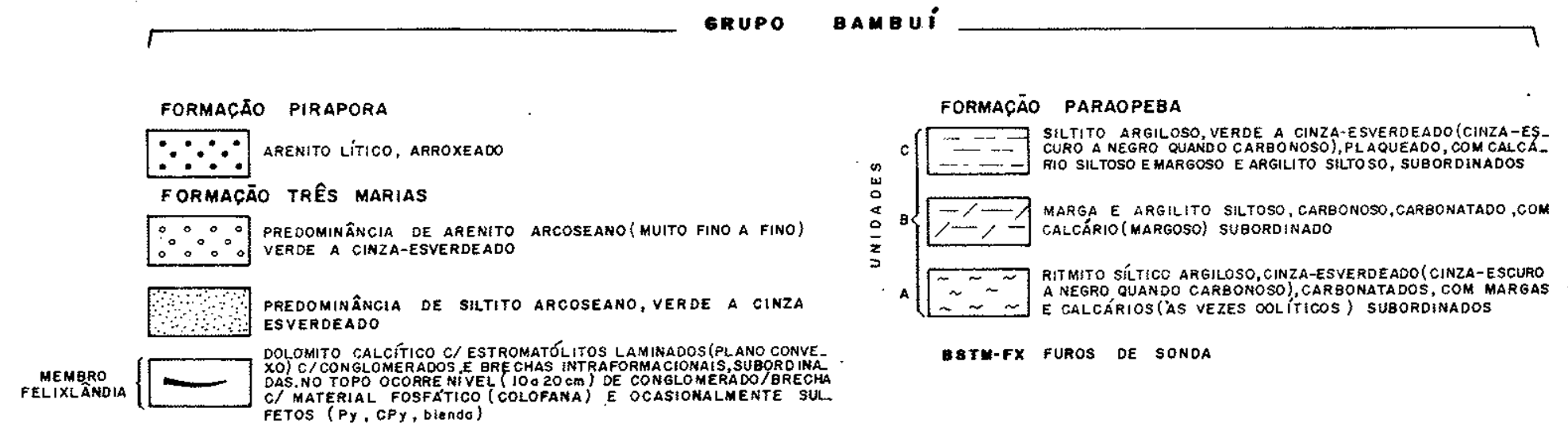

m8tM-Fx fuRos de sonda 
são subordinados, como na serra do Boiadeiro, ou onde adquire significativa expressão, como no morro da $\mathrm{Ca}$ beça. As evidências indicam tratar-se de um biostromo, em que a participação química/bioquímica foi preponderante, estando o fator mecânico, responsável pelas brechas e pelos conglomerados, subordinado.

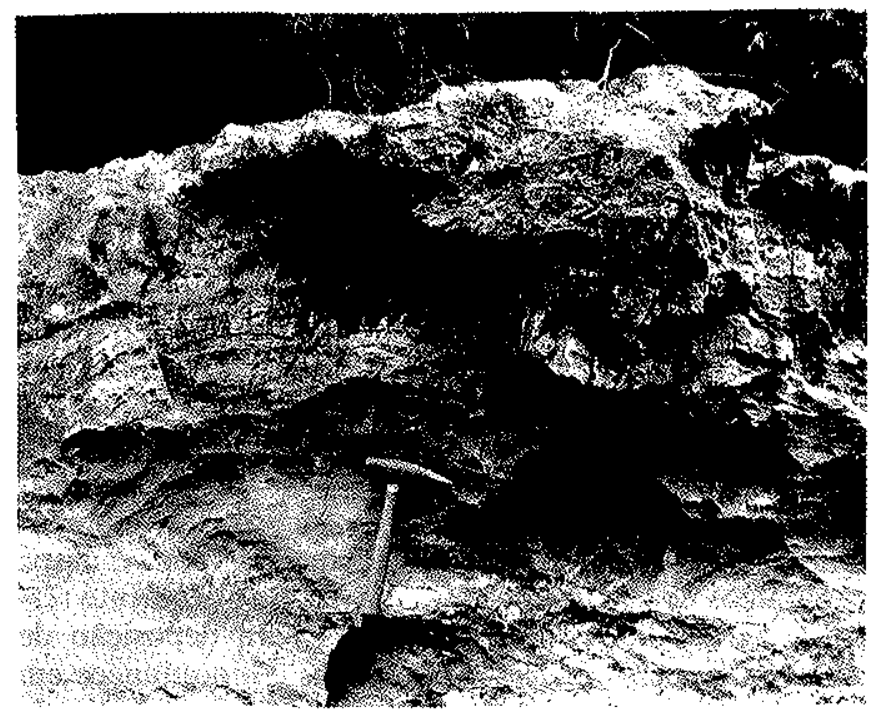

Foto 1 - Fazenda do Tronco. Dolomito com estromatólitos laminados, capeando conglomerado dolomítico (Membro Felixlândia)

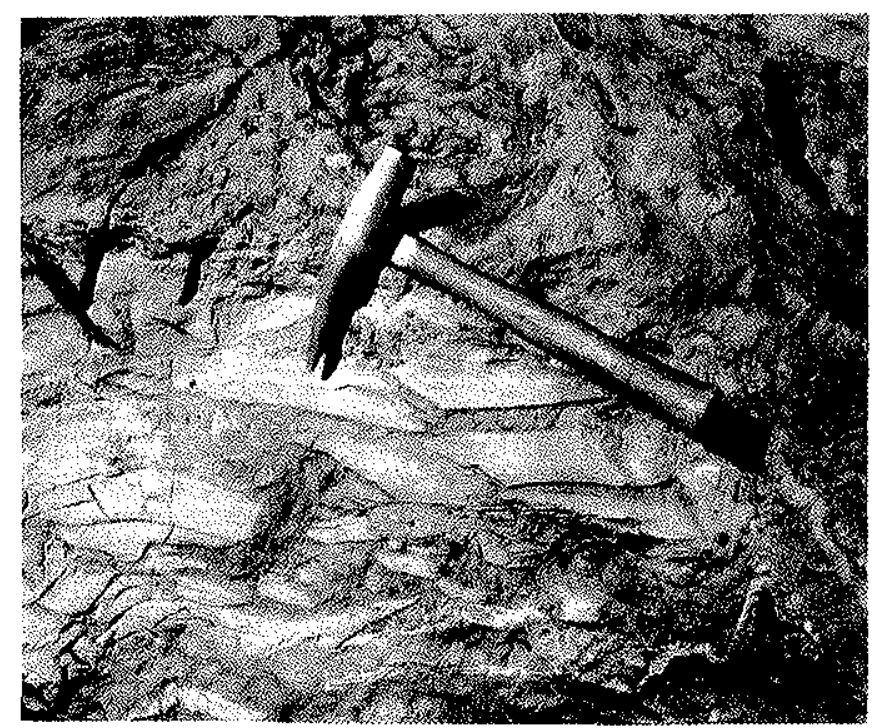

Foto 2 - Serra do Grotão (Pai Pedro). Brecha dolomítica (Membro Felixlândia)

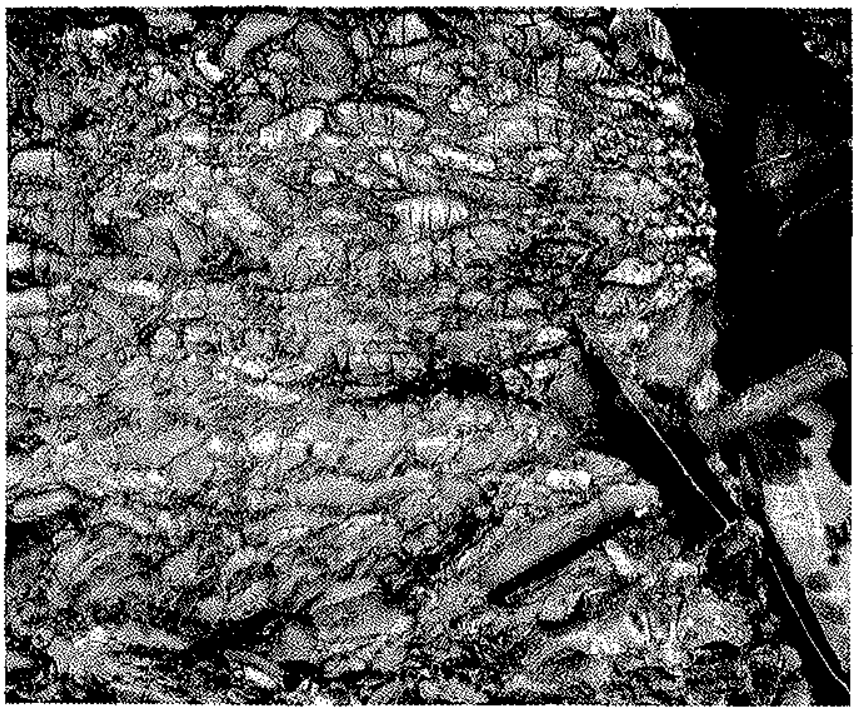

Foto 3 - Serra da Marmelada. Conglomerado dolomítico (Membro Felixlândia)

As relações de contato do Membro Felixlândia com a unidade subjacente (Formação Paraopeba) varia de gradacional, como se observou nos furos de sonda, a brusco, como na área ao norte do ribeirão do Peixe. No primeiro caso, temos a passagem do argilito siltoso de verde a cinza-esverdeado para uma sucessão de siltito dolomítico, dolomito, dolomito brechóide, ligeiramente esverdeados, num intervalo máximo de $15 \mathrm{~cm}$, quando grada a um dolomito sem contribuição de material terrígeno. No segundo caso, tem-se o conglomerado dolomítico repousando diretamente sobre siltitos argilosos em contato brusco.

O contato superior é sempre brusco e irregular. Nota-se, neste caso, que o argilito siltoso do topo penetra irregularmente no dolomito por alguns centímetros, através de fraturas e cavidades irregulares. É feição comum também o contato de o topo ser marcado por fino (10-15 cm) nível de conglomerado escuro ou brecha, onde se observam raros seixos e fragmentos de siltito e calcário, e, quase sempre, a presença de "nódulos" de colofana de formas achatadas ou em níveis com espessura de até $4 \mathrm{~cm}$, de cor negra a cinza-escuro. Também foi observado em certos locais a ocorrência de um microconglomerado com "matriz" abundante composta por quartzo, plagioclásio, sericita e clorita. As cloritas se apresentam como palhetas alongadas devido à diagênese. Os fragmentos de rocha (calcário, filito) mostram-se também alongados segundo uma direção assim como seixos achatados de colofanito. Contém também, às vezes, cristais de pirita e calcopirita. Embora sem comprovação direta, este microconglomerado parece situar-se na interface do topo do Membro Felixlândia e base do pacote de siltito argiloso.

$\mathrm{Na}$ pedreira situada no morro da Cachaça, foi possível observar, a aproximadamente $1 \mathrm{~m}$ acima do Membro Felixlândia, intercalada nos siltitos argilosos, 
uma camada descontínua de dolomito com espessura máxima em torno de $20 \mathrm{~cm}$, tendo no topo fino nível $(2 \mathrm{~cm})$ de colofana e esparsos cristais centimétricos de pirita. Lateralmente, este nível colofânico ultrapassa os limites da camada de dolomito, intercalando-se nos siltitos argilosos. Esse tipo de ocorrência só foi observado neste local e de maneira precária devido às condiçð̌es do afloramento.

Quanto aos conglomerados e às brechas, nota-se, em relação aos seixos e fragmentos, serem da mesma natureza do dolomito, evidenciando tratar-se de retrabalhamento deste sob condições de alta energia ambiental, portanto intraformacionais. A ocorrência no topo de raros seixos e fragmentos de siltito e calcário (nível fosfático) bem como de fragmentos de colofanito, parece indicar um aporte de material exógeno em função das novas condições ambientais que se iniciavam.

$O$ traço estrutural marcante do pacote sedimentar ocorrente na área de pesquisa é um suave mergulho do Membro Felixlândia para o norte, da ordem de 10 a $17 \mathrm{~m} / \mathrm{km}$, portanto um pouco mais acentuado que o observado para a Formação Pirapora (Couto et al., 1978). Um sistema de juntas paralelas verticais, de direção N70-80W e N10-30E, foi observado em toda a área.

O Membro Felixlândia ocorre em toda a extensão da área pesquisada e, pelas descriçðes de Matos et al. (1978), estende-se para leste, até próximo à cidade de Curvelo ( morro da Garça), e para oeste, na regiåo da barragem de Três Marias e no chapadão do oeste mineiro como blocos rolados.

FORMAÇÃo PIRAPORA Esta unidade ocorre na serra do Boiadeiro em pequeno testemunho isolado, com espessura de $4 \mathrm{~m}$. São arenitos líticos arroxeados, friáveis, em contato pouco nítido com a unidade subjacente (Formação Três Marias).

\section{COMENTÁRIOS SOBRE O AMBIENTE DE SEDI- MENTAÇÃO DO MEMBRO FELIXLÂNDIA}

Pelos dados apurados nos trabalhos de pesquisa, um fato significativo chama logo a atenção. Trata-se da passagem do siltito argiloso do topo da Formação $\mathrm{Pa}$ raopeba (unidade C) para o Membro Felixlândia e a repetição da mesma litologia acima deste Membro. Uma interpretação para essa mudança brusca nas condiçðes ambientais, com a interrupção de sedimentos terrígenos passando para uma sedimentação química e bioquimica, e um retorno a sedimentação terrígena, implica uma momentânea interrupção do aporte de sedimentação clástica causada possivelmente por um bloqueio da fontes de sedimentação. As causas são desconhecidas mas é significativo que os sedimentos acima do Membro Felixlândia se tornem mais grosseiros da base para o topo, numa seqüência de siltitos para arenitos arcoseanos, caracterizando de maneira marcante uma regressão.

O Membro Felixlândia, possivelmente, representa uma deposição em plataforma estável, na zona intertidal, em um mar epicontinental de águas rasas, momentaneamente isolado do mar principal por eventos geológicos de causas desconhecidas. Neste ambiente restrito, as condiçð̃es eram propícias para deposição de carbonatos pelos processos químicos e bioquímicos em que o magnésio encontrava condiçðes favoráveis de concentração. Ao se encerrar um ciclo de sedimentação química-bioquímica se reiniciar-se a deposição de sedimentos clásticos, já restabelecidas as ligaçóes com o mar principal, precipita-se o fosfato na forma de colofana.

\section{BIBLIOGRAFIA}

BRAUN, OSCAR P. G. - 1968 - Contribuiç̃o à estratigrafia do Grupo Bambui. Anais do XXII Congresso. Sociedade Brasileira de Geologia. Belo Horizonte, pp. 155-166.

COUTO, J.G. PARENTI - 1979 - Projeto Bambuí Sul - Três Marias; Geologia e Mineralizaçðes na Regiăo de Felixlândia. Belo Horizonte, Metamig (relatório, interno).

COUTO, J. G. PARENTI; ALECRIM, J. D. e PINHEIRO, S. O. - 1978 Reconhecimento geológico-geoquímico das Formaçðes Três Marias e Pira pora (Grupo Bambui). Anais do XXX Congresso. Sociedade Brasileira de Geologia. Recife, vol. 5, pp. 2059-2073.

MATOS, G. M. et al. - 1978 - Formação Três Marias - Grupo Bambuí m Litologia e Estruturas Sedimentares. Anais do XXX Congresso. Sociedade Brasileira de Geologia. Recife, vol. 3, pp. 809-823. 